\title{
Nomenclatura em Química
}

por Ricardo B. de Alencastro ${ }^{1}$

e Roberto de B. Faria ${ }^{2}$
Data de publicação na Web: 28 de Março de 2011 Recebido em 28 de Março de 2011 Aceito para publicação em 28 de Março de 2011

Na química inorgânica, temos três sistemas de nomenclatura na química inorgânica aprovados pela IUPAC (Red Book da IUPAC Nomenclature of Inorganic Chemistry - IUPAC Recommendations 2005):

1. nomenclatura composicional

2. nomenclatura substitutiva (parte do nome de um hidreto primário)

3. nomenclatura aditiva

Além disso, ainda existe uma nomenclatura específica para os ácidos e, também, para outros tipos de compostos, como os compostos de coordenação, os organometálicos, etc.

Discutimos, neste número, um

2. Por que formato e não formiato. Pela mesma razão.

fórmico - ico = form; form + ato = formato. Alguns dicionários, inclusive o Dicionário da L.P. da Porto Editora, registra formiato, dando a derivação, obviamente errada, formico - co = formi; formi + ato $=$ formiato.

3. Em muitos trabalhos publicados em português e em teses e dissertações aparece, corretamente, a forma glicose (e não glucose) de que a raiz é "glic". Esta raiz deve se manter em todos os nomes derivados. Assim, ácido glicônico (e não glucônico), ácido glicárico(e não glucárico) etc. É um erro relativamente comum e muito fácil de ser corrigido. caso interessante, os nomes dos compostos $\quad \mathrm{NaBH}_{4}, \quad \mathrm{LiAlH}_{4}$, $\mathrm{NaBH}_{3} \mathrm{CN}$ e $\mathrm{LiC}_{4} \mathrm{H}_{9}$, usados rotineiramente em laboratórios de sínteses, e que são chamados comumente de boro-hidreto de sódio, hidreto de alumínio e lítio, cianoboro-hidreto de sódio e butillítio, respectivamente.

\section{Nomenclatura Composicional}

Exige que se separe os constituintes do composto em formalmente eletropositivos e eletronegativos. Aplica-se principalmente quando não se tem ou não se quer considerar informações estruturais. Descreve apenas a composição do composto. Por este tipo de nomenclatura, em nosso caso, teremos (regra IR-5.4.1, pg. 75):
1. Por que halogeneto e não

haleto?

Alguns modos de escrever, impróprios, mas correntes na literatura em português no Brasil: 
$\mathrm{NaBH}_{4}$ - tetra-hidreto de boro e sódio (ordem alfabética dos nomes dos componentes eletropositivos);

$\mathrm{LiAlH}_{4}$ - tetra-hidreto de alumínio e lítio (ordem alfabética dos nomes dos componentes eletropositivos);

$\mathrm{NaBH}_{3} \mathrm{CN}$ - cianeto e tri-hidreto de alumínio e boro (ordem alfabética dos componentes eletronegativos e dos componentes eletropositivos).

\section{Nomenclatura Substitutiva}

Parte do nome do hidreto primário:

$\mathrm{BH}_{3}$ - borano;

$\mathrm{AlH}_{3}$ - alumano;

$\mathrm{PH}_{3}$ - fosfano.

Ao se formar um ânion pela adição de um íon hidreto usa-se a terminação "uide" que podemos adaptar para o português como "ueto", para diferenciar-se da nomenclatura dos ânions (-eto). Assim:

\section{$\left[\mathrm{BH}_{4}\right]^{-}$- boranueto}

$\left[\mathrm{AlH}_{4}\right]^{-}$- alumanueto

Dessa forma, teremos:

$\mathrm{NaBH}_{4}$ - boranueto de sódio; $\mathrm{LiAlH}_{4}$ - alumanueto de lítio;

$\mathrm{NaBH}_{3} \mathrm{CN}$ - cianoboranueto de sódio.

\section{Nomenclatura Aditiva}

Foi originalmente desenvolvida para os compostos de coordenação.

Os ânions complexos são indicados pela terminação "ato".

A nome dos ligantes aniônicos terminam sempre em "o" (ex. fluorido, clorido, bromido, iodido, hidrido, cianido, etc.).

$\left[\mathrm{BH}_{4}\right]^{-}$- tetra-hidridoborato $(-1)$

$\left[\mathrm{AlH}_{4}\right]^{-}$- tetra-hidridoaluminato $(-1)$

Dessa forma, teremos:

$\mathrm{NaBH}_{4}$ - tetra-hidridoborato (-1) de sódio;

$\mathrm{LiAlH}_{4}$ - tetra-hidridoaluminato (-1) de lítio;

$\mathrm{NaBH}_{3} \mathrm{CN}$ - cianidotrihidridoborato (-1) de sódio (como o $\mathrm{CN}$ está ligado ao $\mathrm{B}$, é nomeado como um ligante).

\section{Nomenclatura de Organometálicos}

Compostos organometálicos são definidos como sendo aqueles que possuem, pelo menos, uma ligação entre um átomo metálico e um átomo de carbono. Essa definição algumas vezes não é seguida estritamente, usando como critério o comportamento (reatividade) da substância. Por exemplo, a espécie $\left[\mathrm{Fe}(\mathrm{CN})_{6}\right]^{3+}$, que deveria claramente ser considerada um organometálico é, na verdade, considerada um composto de coordenação.

Novamente, temos três tipos de nomenclatura diferentes:

1. compostos organometálicos de metais de transição: a nomenclatura se baseia na nomenclatura aditiva usada para os compostos de coordenação;

2. compostos organometálicos envolvendo elementos dos grupos 13 ao 16: usa-se a nomenclatura substitutiva que toma como base o nome dos hidretos primários;

3. compostos organometálicos envolvendo elementos dos grupos 1 e 2: baseia-se também na nomenclatura aditiva.

Para o caso específico do $\mathrm{LiC}_{4} \mathrm{H}_{9}$, considerando $\mathrm{O}$ grupamento orgânico como um ligante ao átomo de $\mathrm{Li}$, usamos o nome do ligante orgânico neutro:

$$
\begin{array}{ll}
\mathrm{CH}_{3}- & \text { metil } \\
\mathrm{CH}_{3} \mathrm{CH}_{2}- & \text { etil } \\
\mathrm{CH}_{3}\left(\mathrm{CH}_{2}\right)_{2} \mathrm{CH}_{2}- & \text { butil }
\end{array}
$$

Assim, o $\mathrm{LiC}_{4} \mathrm{H}_{9}$ é chamado, corretamente, de butil-lítio, onde o hífen foi acrescentado devido à presença de duas letras idênticas que não podem ser suprimidas sem perda de sentido químico.

1. Universidade Federal do Rio de Janeiro (UFRJ), Instituto de Química, Centro de Tecnologia Bloco A, sala 609 Ilha do Fundão, Rio de Janeiro. 21941-590, RJ, Brasil. M bicca@iq.ufri.br

2. Universidade Federal do Rio de Janeiro (UFRJ), Instituto de Química, Centro de Tecnologia Bloco A, sala 630 Ilha do Fundão, Rio de Janeiro. 21941-590, RJ, Brasil. M faria@iq.ufri.br 